\title{
Food intake and work allocation of male and female farmers in an impoverished Indian village
}

\author{
BY W. C. EDMUNDSON* AND S. A. EDMUNDSON \\ Department of Biometry, Maharashtra Association for the Cultivation of Science, \\ 411004 Pune, India
}

(Received 26 February 1988-Accepted 20 July 1988)

1. The energy balance and activity allocation of eight male and eight female Indian farmers were meaured for $4 \mathrm{~d}$ during 10 months in both the dry and wet seasons of 1983.

2. All food prepared and eaten was weighed and nutrient values were calculated from food composition tables.

3. Average energy costs per unit mass for fifteen tasks were estimated from data obtained using a Kofranyi-Michaelis respirometer. Each subject was observed from 05.00 to 20.00 hours and activities were recorded for each minute. The remaining activity was determined by recall.

4. Activity allocation was categorized qualitatively into time spent on economically productive work, free time and body maintenance.

5. The mean weight for male subjects was $48.2 \mathrm{~kg}$; the average female weight was only $36.9 \mathrm{~kg}$. The mean height for male and female subjects was $1.61 \mathrm{~m}$ and $1.49 \mathrm{~m}$ respectively.

6. For male subjects, the daily mean energy intake of $9.81 \mathrm{MJ}(2350 \mathrm{kcal})$ was close to the calculated energy output of $9.54 \mathrm{MJ}(2285 \mathrm{kcal})$.

7. The women's calculated daily expenditure of 8.22 MJ (1968 kcal) was slightly higher than their mean energy intake of $7.73 \mathrm{MJ}$ (1852 kcal).

8. Although intake and output varied in relation to sex, weight and wealth the mean intake per $\mathrm{kg}$ body mass was equal for both males and females at $210 \mathrm{~kJ}(50 \mathrm{kcal})$ per $\mathrm{kg}$. This is close to the minimum requirement for active Third World farmers.

9. The women spent significantly more time on economically productive work activities than the men $(11 \cdot 1 \mathrm{v}$. $8 \cdot 1 \mathrm{~h} / \mathrm{d}$ ). Although female energy intake was $27 \%$ less than males, their productive work time was $27 \%$ higher.

Few detailed measurements of human energy balance and time allocation have been made in the developing world. In some of these studies it was found that the average food intake and energy expenditure were in agreement (Hipsley \& Kirk, 1965; Edmundson, 1976; Moji, 1987) but in other studies a negative energy balance was recorded (Norgan et al. 1974; Bleiberg et al. 1981). However, all these authors mentioned that their subjects were hard working and reasonably healthy in spite of low intakes.

In Java we found wide variation in energy intake for subjects of similar stature engaged in farm activities. There was little correlation between individual energy intake and output $(r 0.04)$. Workers with low intakes were as productive as workers with high energy intakes. This led us to suggest there were significant inter-individual variations in basal metabolic rate, mechanical work efficiency and the percentage of time spent working (Edmundson, 1976). Closer examination of selected high- and low-intake subjects with the same height and weight confirmed group differences in basal metabolic rate (BMR) of the order of 2:1 (Edmundson, 1977, 1978, 1980). Our previous studies examined only male subjects.

\footnotetext{
* Present address: Department of Geography, University of New England, Armidale, N.S.W. 2351, Australia.
} 


\section{BACKGROUND AND METHODOLOGY}

\section{Ecological setting}

The study began in January 1983 but information was collected from May to November after the subjects were at ease with the researchers. Katavi village has 326 people occupying 221 ha dry land $120 \mathrm{~km}$ east of Bombay. Located on the barren Deccan Plateau at an elevation of $680 \mathrm{~m}$, it receives only $620 \mathrm{~mm}$ of rain during the monsoon from May through October and only $200 \mathrm{~mm}$ during the rest of the year. The dry-season means temperature was $34^{\circ}$ with a relative humidity of $53 \%$ while the wet season temperature averaged $28^{\circ}$ with $78 \%$ relative humidity. There was no road into the village and drinking water was obtained from the Indrayani river. There were less than 20 ha of alluvial black soil floodplain. Sorghum yields were very low $(900 \mathrm{~kg} / \mathrm{ha})$ and the small plots of rain-fed rice yielded only $1700 \mathrm{~kg} / \mathrm{ha}$ once per year. Land preparation was poor, there was no irrigation, no high-yielding grains were planted, and no artificial fertilizer was used.

With the exception of three outcaste families, all villagers belonged to the Marathi farming caste and all were very poor with few possessions. Most owned some dry land. None owned irrigated land. Some male subjects worked in Poona $22 \mathrm{~km}$ to the east for a wage of about $\$ 40$ (US)/month.

\section{Subjects}

A total of sixteen Hindu villagers (eight male and eight female) were subjects with their full consent. These were a sample of upper- middle- and lower-class families selected with the help of the village chief. All subjects were adults between 25 and 40 years of age with no metabolic disease. None of the women were pregnant or lactating at the start of this survey. The two principal researchers could communicate in the local language, and were accompanied by Marathi-speaking assistants. No subjects were observed during periods of active illness but many suffered from influenza during the survey.

\section{Anthropometric measurements}

Body-weight and height. Anthropometric measurements were made by a single trained observer. Subjects were weighed in their home to the nearest $\mathrm{kg}$ in their clothes minus shoes on a bathroom scale checked and calibrated with a beam balance. Height was simultaneously recorded to the nearest $2 \mathrm{~mm}$, using a weighted steel tape and a ruler.

Skinfold thicknesses and percentage fat. Harpenden skinfold calipers were used to measure skinfolds at the triceps, subscapular and suprailiac sites on the left side of the body. Body density was calculated using the three-site regression equation for the appropriate age and sex as published by Durnin \& Womersley (1974). Percentage fat was estimated using the Siri (1956) equation. Anthropometric values are presented in Table 1.

\section{Nutrient intake}

One research assistant weighed raw ingredients, including spices, for each recipe on a standard dietary scale accurate to within $2 \mathrm{~g}$. The weight of the cooked recipe was obtained to determine water gained or lost. The total nutrient values for raw ingredients were calculated from Indian Food Composition Tables (Gopalan et al. 1982). These values were divided by the cooked weight of the recipe in $\mathrm{g}$ to determine nutrients per $\mathrm{g}$ for each recipe. Individual servings were weighed before eating and plate waste was substracted. Nutrient values per $g$ were multiplied by weight of food ingested to calculate intake.

\section{Energy output and activity records}

The methodology used has been described in previous papers (Edmundson, 1977, 1978) and constructively evaluated by Grossman (1984) and Moji (1987). Fifteen activities were 
Table 1. Physical characteristics of male and female Indian farmers

(Mean values and standard deviations for eight subjects per group)

\begin{tabular}{|c|c|c|c|c|}
\hline & \multicolumn{2}{|c|}{ Males } & \multicolumn{2}{|c|}{ Females } \\
\hline & Mean & SD & Mean & SD \\
\hline Age (years) & $33 \cdot 2$ & $4 \cdot 4$ & $28 \cdot 1$ & $5 \cdot 0$ \\
\hline Height (m) & $1 \cdot 61$ & $0 \cdot 044$ & 1.49 & 0.048 \\
\hline Wt (kg) & $48 \cdot 2$ & $1 \cdot 4$ & 36.9 & $4 \cdot 2$ \\
\hline \multicolumn{5}{|l|}{ Skinfold (mm) } \\
\hline Triceps & $9 \cdot 4$ & $3 \cdot 2$ & $9 \cdot 7$ & $5 \cdot 5$ \\
\hline Subscapular & $9 \cdot 1$ & $1 \cdot 3$ & $9 \cdot 4$ & $4 \cdot 4$ \\
\hline Suprailiac & $13 \cdot 7$ & $3 \cdot 9$ & $9 \cdot 7$ & $4 \cdot 6$ \\
\hline Percentage fat & 17.0 & $3 \cdot 9$ & $21 \cdot 2$ & $5 \cdot 0$ \\
\hline
\end{tabular}

calculated in terms of physiological energy cost $/ \mathrm{kg}$ per min for each task and categorized in relation to their productive or non-productive character.

Each subject was followed by an observer throughout four waking days about 1.5 months apart. The time spent in fifteen basic activities was noted on a minute-by-minute basis. The BMR and the energy costs of the main activities were measured using a Kofranyi-Michaelis respirometer and the expired air was analysed in duplicate by two separate researchers using a Micro-Scholander gas analyser at the Maharashtra Association for the Cultivation of Science (MACS) in Poona. Activity values not measured directly were taken from previous survey information for Indonesian villagers (Edmundson, 1976). To calculate the expenditure for each activity, the mean value for all individual measurements was used. Estimates were adjusted by dividing the average energy cost for each activity by the average weight of the subjects. Individual tasks were added to obtain the average energy cost $/ \mathrm{kg}$ per min per task. This value was then multiplied by the subject's weight and by the period of time (min) the subject engaged in that activity. All tasks were added to calculate daily energy output. The BMR for all subjects was measured at 05.00 hours during the last month of the survey and the average BMR for each sex was used to calculate the energy cost of lying down and sleeping (Table 2).

\section{Qualitative activity allocation}

Each activity period was assigned a socio-economic character of productive work, free time or body maintenance. Work was defined as any activity which resulted in or contributed to a change in form or place utility. Thus a journey to and from the fields as well as all labour in the fields constituted work. Housework, child minding, fetching water and the tending of cattle were all work tasks. Social and religious activities including attendance at weddings and funerals were categorized as free time. Body maintenance included sleeping, eating, grooming, bathing and defaecating.

\section{RESULTS \\ Energy intakes}

The mean daily energy intakes were $9.81 \mathrm{MJ}(2350 \mathrm{kcal})$ and $7.73 \mathrm{MJ}(1852 \mathrm{kcal})$ for the males and females respectively. For both sexes the energy intake was $84 \%$ of the respective Indian reference recommendation (Gopalan et al. 1982). The average energy intake per $\mathrm{kg}$ body-weight was about $210 \mathrm{~kJ}(50 \mathrm{kcal})$ for both men and women. Thus, although energy intake was significantly different between the sexes, the energy intake per unit mass was 
Table 2. Energy cost for work tasks and resting (lying down) for Indian farmers

(Mean values and standard deviations)

\begin{tabular}{|c|c|c|c|c|c|}
\hline \multirow[b]{3}{*}{ Activity } & \multirow{3}{*}{$\begin{array}{c}\text { No. of } \\
\text { subjects* }\end{array}$} & \multicolumn{4}{|c|}{ Energy cost (/kg per min) } \\
\hline & & \multicolumn{2}{|c|}{$\mathrm{kJ}$} & \multicolumn{2}{|c|}{ kcal } \\
\hline & & Mean & SD & Mean & SD \\
\hline \multicolumn{6}{|l|}{ Resting: } \\
\hline males & 8 & $0 \cdot 075$ & 0.017 & 0.018 & 0.004 \\
\hline females & 8 & 0.084 & 0.013 & 0.020 & 0.003 \\
\hline Sitting & 24 & $0 \cdot 109$ & 0.018 & 0.026 & 0.004 \\
\hline Squatting & 6 & 0.113 & 0.018 & 0.027 & 0.004 \\
\hline Standing & 20 & 0.126 & 0.020 & 0.030 & 0.005 \\
\hline Strolling & 5 & 0.180 & $0 \cdot 021$ & 0.043 & 0.005 \\
\hline Cooking & 6 & $0 \cdot 167$ & 0.008 & 0.040 & 0.002 \\
\hline Walking & 16 & 0.226 & 0.042 & 0.054 & 0.010 \\
\hline Housework & 4 & 0.243 & $0 \cdot 054$ & 0.058 & 0.013 \\
\hline Light work & 8 & $0 \cdot 184$ & 0.033 & 0.044 & 0.008 \\
\hline Light carrying & 4 & 0.385 & 0.054 & 0.092 & 0.013 \\
\hline Heavy carrying & 7 & 0.498 & 0.079 & 0.119 & 0.019 \\
\hline Ploughing & 2 & 0.544 & 0.017 & 0.130 & 0.004 \\
\hline Medium work & 10 & 0.264 & 0.100 & 0.063 & 0.024 \\
\hline Hoeing & 6 & 0.318 & 0.063 & 0.076 & 0.015 \\
\hline Heavy work & 6 & 0.460 & 0.071 & $0 \cdot 110$ & 0.017 \\
\hline
\end{tabular}

* Except for basal metabolic rate, cooking and housework, all values refer to male subjects.

the same. This value of $210 \mathrm{~kJ}(50 \mathrm{kcal}) / \mathrm{kg}$ is probably close to the minimum energy requirement necessary for subsistence farming.

\section{Energy output and economic activity}

Pattern of activities. Women spent more of their day working than did men. The females dedicated $46.2 \%$ of their time $(11 \cdot 1 \mathrm{~h} / \mathrm{d})$ to economically productive work activity. On average, $33.9 \%(8.1 \mathrm{~h} / \mathrm{d})$ of the men's time was spent working. Both sexes worked a $7 \mathrm{~d}$ week but only the males were able to rest during the many festivals. Wives worked as hard as usual during festivals. Those husbands who worked in factories had a half-day holiday on Thursday and a full day off on Sunday. However, the young men who worked in factory service had to help their fathers in the fields on Sundays. Counting housework, women spent on average $77.6 \mathrm{~h}$ working/week $v .57 .0 \mathrm{~h} /$ week for males. This difference was found to be highly significant using the Mann-Whitney ranked $T$ test $(P<0.01)$.

In terms of body maintenance activities, the males and females of Katavi village were not significantly different. The men spent $38.3 \%$ of their time or $9 \cdot 2 \mathrm{~h} / \mathrm{d}$ engaged in sleeping, eating and personal hygiene, and the women $39.1 \%$ of their time or $9.4 \mathrm{~h} / \mathrm{d}$. The men averaged $27.8 \%$ or $6.7 \mathrm{~h}$ of their day in free time or in social activity, while the women had only $14.7 \%$ or $3.5 \mathrm{~h}$ of their day free. It is clear that these women allocated more of their time to economic activity and less to rest and social activity than males.

\section{Energy expenditure}

The mean total daily physiological energy expenditure for male villagers was $9 \cdot 56 \mathrm{MJ}$ $(2285 \mathrm{kcal})$. Total energy expenditure for women was 8.22 MJ (1968 kcal). Although the males thought they worked extremely hard, the females worked much longer hours at moderate levels of intensity. The men did perform slightly more heavy work than the 
Table 3. Energy input and output for male and female Indian farmers

(Mean values and standard deviations)

\begin{tabular}{|c|c|c|c|c|c|c|c|c|c|}
\hline & \multirow[b]{3}{*}{$n$} & \multicolumn{4}{|c|}{ Energy input $(/ d)$} & \multicolumn{4}{|c|}{ Energy output (/d) } \\
\hline & & \multicolumn{2}{|c|}{ MJ } & \multicolumn{2}{|c|}{$\mathrm{kcal}$} & \multicolumn{2}{|c|}{ MJ } & \multicolumn{2}{|c|}{ kcal } \\
\hline & & Mean & SD & Mean & SD & Mean & $\overline{\text { SD }}$ & $\widehat{\text { Mean }}$ & SD \\
\hline Males & 8 & 9.81 & $0 \cdot 19$ & 2350 & 455 & 9.56 & $0 \cdot 12$ & 2285 & 300 \\
\hline Females & 8 & 7.73 & $0 \cdot 12$ & 1852 & 293 & $8 \cdot 22$ & 0.11 & 1968 & 255 \\
\hline Total & 16 & 8.77 & 0.16 & 2101 & 475 & 8.88 & 0.12 & 2126 & 278 \\
\hline
\end{tabular}

There were no statistically significant differences in input and output.

females, but this level of activity (more than $25 \mathrm{~kJ}(6 \mathrm{kcal}) / \mathrm{min}$ ) occupied only $14.5 \mathrm{~min} / \mathrm{d}$ on average. The males spent more time doing light work than the females. The women spent the majority of their waking time in activities of moderate intensity. They also spent $34.5 \mathrm{~min} / \mathrm{d}$ carrying water. This was 'heavy work' on the uphill return portion of the carry. Both men and women exhibited high levels of energy expenditure at the peak of the planting and harvesting period, but men were able to rest more than women during the rest of the year.

\section{Energy balance and imbalance}

For all subjects adult energy intake was $8.77 \mathrm{MJ}(2101 \mathrm{kcal})$ and output was estimated to be $8.88 \mathrm{MJ}(2126 \mathrm{kcal}) / \mathrm{d}$. When the total sample was considered, there was a low, non-

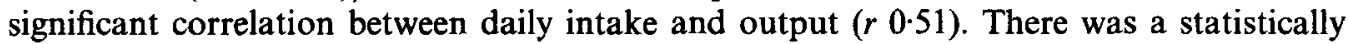
significant, but still modest correlation of $r 0.70$ between $4 \mathrm{~d}$ averages of measured energy intake and estimated total energy output $(P<0.03)$. Mean energy intake explained only $49 \%$ of the variation in mean output. This lack of consistent balance for individual values is not surprising. The homeostatic mechanism which controls and governs energy balance as described by Sukhatme \& Margen (1982) involves a complex and long-term lag mechanism. If there were more sample days and these days were contiguous, the correlation should approach unity.

For all men the mean energy intake was $9.81 \mathrm{MJ}(2350 \mathrm{kcal})$ and the average output was $9.56 \mathrm{MJ}(2285 \mathrm{kcal}) / \mathrm{d}$. These averaged intakes and outputs were in agreement. For all women the mean energy expenditure of $8.22 \mathrm{MJ}(1968 \mathrm{kcal})$ appeared to exceed the mean energy intake of $7.73 \mathrm{MJ}(1852 \mathrm{kcal}) / \mathrm{d}$. Even though not statistically significant, this difference is surprising. The apparent imbalance is perhaps an artifact of the methodology in which the average energy cost per $\mathrm{kg}$ for each task was derived primarily from male values. The lower-intake females may have been able to perform many of the fifteen work tasks at lower than average estimated costs even after adjusting for weight differences. Values for apparent energy balance and imbalance by group is illustrated in Table 3.

\section{DISCUSSION}

There are many sources of inaccuracy in assessing daily energy expenditure using average costs of work tasks for individuals who may vary in how energetically they perform that task. Even if all individuals performed all tasks in a similar manner, the application of average costs to individuals will fail to account for differences in individual metabolic efficiency. There is a clear need for improved methodology, longer study periods, and a 
better understanding of the social and physiological mechanisms for adaptation to low levels of energy intake and the regulation of energy balance. However, comparisons of group performances and apparent energy balances and imbalances are useful as first-order approximations of relative efficiency; they provide clear information on time allocation, and can be used to suggest hypotheses for detailed study under controlled conditions.

The present study of food and work of poor subjects living in an unhealthy and hostile environment found that males ate more and spent less time on productive work than females. The sex difference in time allocation explains the small negative correlation between energy intake and time devoted to work. Although the women ate less, they worked longer. In this case there was an inverse relation between energy intake and time devoted to productive work. This variation represents a socio-economic adaptation to low intakes where individuals on a low plane of nutrition expend a greater proportion of time on productive work tasks. Energy intake has little relation to productive work output (see Edmundson, 1977; Immink \& Viteri, 1981), because poor individuals are forced to devote a higher proportion of their time to work. Third World women, whose energy intakes are about $30 \%$ lower than males, generally allocate about $30 \%$ more of their time to productive economic work (Norgan et al. 1974; White, 1980; François et al. 1983). There is no reason to assume that human energy intake need be related to economically productive work output if low-intake groups consistently devote more of their time to work. The economic implications of this social process are vast, but at present appear to be very poorly understood.

The lack of strong correlation between daily intake and output should arise naturally in a model of energy regulation where serial autocorrelation in energy balance implies a timelag structure in adjustment to a series of temporary imbalances (Sukhatme \& Margen, 1982). Although homeostatic adaptation will bring long-term balance in the absence of change in body mass or composition, input and output are only occasionally in phase on a given day. More than 20 years ago Durnin (1961) noted that out of sixty-nine individual subjects studied for $7 \mathrm{~d}$, " 59 showed no significant correlation whatsoever between their energy intake and the energy expended on any one day'. Most of us are aware that our intake and output are often not in balance on a daily basis. We may be 'too busy to eat' during heavy work days but holidays are a time of feasting and relaxation.

The finding that the standard error for average energy intake was much higher than the standard error for mean energy expenditure, as illustrated in Table 3, has been noted before (Hipsley \& Kirk, 1965; Norgan et al. 1974; Edmundson, 1976; Bleiberg et al. 1981). This may be caused by two factors. First, the pattern of daily activity tends to be more constant and less variable than food intake. Second, methods of measurement for intake and output were different in potential for error. The type, source and variety of food eaten were similar for all villagers, and the energy content of a given food source varied little. Using the average energy value to calculate intake was thus accurate. However, inter-individual variability in metabolic efficiency is quite high. Thus, using average energy costs to calculate output for an individual was less exact. This methodological problem is common to all field investigations of energy balance. To obtain highly accurate information on energy expenditure of individuals in the field, it will be necessary to calibrate the energy costs for each task for each individual separately, but this will be incredibly difficult.

These energy leads and lags combined with a high level of individual variability can explain the lack of correlation between measured intakes and expenditures for individual subjects, but cannot readily explain the lack of close agreement between group female intakes and outputs. With thirty-two full days of observation, this order of difference in group inputs and outputs does deserve comment. The lack of energy balance for all females may be caused by variatons in human metabolic efficiency resulting in consistent errors in 
the underestimation of energy output for individuals on a higher plane of nutrition and the overestimation of energy costs for subjects on a lower energy intake (Edmundson, 1976, 1980) and especially low-intake, high-efficiency females (Bleiberg et al. 1981).

To confirm the exact range of differences in the village situation, a select group of subjects who appear to have unusually high and low levels of efficiency during field study should be studied in detail in a laboratory to determine the absolute range of interindividual variation. After this, the high-intake group should have their ad lib. energy intake decreased and the low-energy group should have their habitual intake increased by a like amount. Then both groups should be tested to determine the range of intra-individual adaptive variation.

We can be sure that significant levels of variation and adaptability do exist. It is clear that there are social and physiological processes including restriction of discretionary activity, increase in allocation of time devoted to economic activity, growth retardation and changes in the metabolic efficiency of energy conversion which enable individuals on a low plane of nutrition, and especially poor women, to maintain a high level of economic productivity even under conditions of dire poverty.

This study was supported by the Indo-American Senior Fulbright Fellowship Program with the special assistance of Professor P. V. Sukhatme, President of the Maharashtra Association for the Cultivation of Science (MACS) in Poona, India.

\section{REFERENCES}

Bleiberg, F., Brun, T., Goiham, S. \& Lippman, D. (1981). British Journal of Nutrition 45, 505-514.

Durnin, J. V. G. A. (1961). Journal of Physiology 156, 294-309.

Durnin, I. V. G. A. \& Womersley, I. (1974). British Journal of Nutrition 32, 77-97.

Edmundson, W. (1976). Land, Food and Work in Three Javanese Villages. Armidale, Australia : University of New England Monograph Series.

Edmundson, W. (1977). Ecology of Food and Nutrition 6, 147-151.

Edmundson, W. (1978). Ecology of Food and Nutrition 8, 189-195.

Edmundson, W. (1980). Social Science and Medicine 14D, 116-121.

Francois, P., Dubois, J. \& Yai, E. (1983). Food and Nutrition 9, 30-37.

Gopalan, C., Rama Sastri, B. V. \& Balasubramanian, S. V. (1982). Nutritive Value of Indian Foods. New Delhi: Indian Council of Medical Research.

Grossman, L. S. (1984). Professional Geographer 36 (4), $444-454$

Hipsley, N. H. \& Kirk, N. (1965). Studies of Dietay Intake and Expenditure by New Guineans. Technical Report no. 147. Noumea: South Pacific Commission.

Immink, M. C. D. \& Viteri, F. E. (1981). Journal of Development and Economics 9, $230-287$.

Moji, K. (1987). In Human Ecology of Health and Survival in Asia and the South Pacific, pp. 165-184 [T. Suzuki and R. Ohtsuka, editors]. Tokyo: University of Tokyo Press.

Norgan, N., Ferro-Luzzi, A. \& Durnin, J. V. G. A. (1974). Philosophical Transactions of the Royal Society, London B 268, 309-348.

Siri, N. E. (1956). In Advances in Biological and Medical Physics [J. H. Lawrence and C. A. Tobias, editors]. London and New York: Academic Press.

Sukhatme, P. V. \& Margen, S. (1982). American Journal of Clinical Nutrition 35, 355-365.

White, B. (1980). In Agricultural and Rural Development in Indonesia [G. Hansen, editor]. Boulder, Colorado: Westview. 